\title{
The efficacy of training of stress-coping strategies on marital satisfaction of spouses of veterans with post- traumatic stress disorder
}

Seyed kaveh Hojjat ${ }^{1}$, Seyed Esmaeil Hatami ${ }^{2}$, Mahdi Rezaei ${ }^{3}$, Mina Norozi Khalilii ${ }^{4}$, Moosa Reza Talebi ${ }^{5}$

${ }^{1}$ MD, Psychiatrist, Assistant Professor, Addiction and Behavioral Sciences Research Center, North Khorasan University of Medical Sciences. Bojnurd, Iran

${ }^{2}$ M.Sc. of Epidemiology, Addiction and Behavioral Sciences Research Center, North Khorasan University of Medical Sciences, Bojnurd, Iran

${ }^{3}$ MA of Clinical Psychology, Addiction and Behavioral Sciences Research Center, North Khorasan University of Medical Sciences, Bojnurd, Iran

${ }^{4}$ MD, Department of Community Medicine and Ethics, Faculty of Medicine, North Khorasan University of Medical Sciences, Bojnurd, Iran

${ }^{5}$ MA of General Psychology, Department of Psychology, Tonekabon Branch, Izlamic Azad University, Tonekabon, Iran

\section{Type of article: Original}

\begin{abstract}
Introduction: Marital satisfaction is an important factor in people's quality of life. It has become increasingly crucial in healthcare and health research and is dependent on coping styles of people exposed to traumatic events. The aim of this study was to assess the effectiveness of coping-style training on increasing the marital satisfaction of wives of veterans with post-traumatic stress disorder (PTSD).

Methods: In this experimental study, 60 subjects were selected from the spouses of veterans with PTSD. The veterans were chosen from the Veterans Foundation of Northern Khorasan Province (Iran) in 2014. In this study, we used the Enrich questionnaire to determine the marital satisfaction of the aforementioned spouses. Subjects were assigned randomly to study and control groups. We used the training package of a Practical Guide for Stress Management according to cognitive behavioral approaches. Cognitive-behavioral group therapy was administered in 90-minute sessions over a 12-week period. We used the paired-samples t-test and ANCOVA to determine the effect of Cognitive Behavior Therapy (CBT) between the two groups.

Results: The mean and the standard deviation of age in the study and control groups were $36.8 \pm 4.33$ years and $35.3 \pm 4.7$ years, respectively. According to $\mathrm{p}<0.005$, a significant difference was observed between the subjects in the two groups. Therefore, treatment with cognitive behavioral group therapy showed evidence of clinical improvements in marital satisfaction of the study group.

Conclusion: The results of our study showed that methods of coping with stress based on CBT are effective in increasing the marital satisfaction of wives of veterans with PTSD.
\end{abstract}

Keywords: marital satisfaction, post-traumatic stress disorder (PTSD), quality of life, coping style

\section{Introduction}

Physical and psychological complications caused by war remain in veterans for a long time. Post-traumatic stress disorder (PTSD) is a common mental disorder among soldiers and veterans returning from war (1). PTSD is an anxiety disorder that occurs following exposure to traumatic events. A person with the symptoms of PTSD responds to traumatic experience by fear of failure (2). Individuals with PTSD in the face of trauma develop high levels of anxiety. They are unable to cope with routine living conditions (2). Also, patients with PTSD have a lower quality of life than patients with other anxiety disorders (3-5). Marital satisfaction is an important factor in people's quality of

\section{Corresponding author:}

Mahdi Rezaei, Addiction and Behavioral Sciences Research Center, North Khorasan University of Medical Sciences, Bojnurd, Iran. Tel: +98.58332211008, Email: Mehradpsy@gmail.com

Received: November 23, 2015, Accepted: March 05, 2016, Published: April 2016 iThenticate screening: March 05, 2016, English editing: March 25, 2016, Quality control: April 02, 2016

(C) 2016 The Authors. This is an open access article under the terms of the Creative Commons Attribution-NonCommercialNoDerivs License, which permits use and distribution in any medium, provided the original work is properly cited, the use is non-commercial and no modifications or adaptations are made. 
life. People's quality of life and marital satisfaction have become increasingly important in healthcare and health research. A number of studies have shown that traumatic life events have a negative impact on quality of life $(6,7)$. PTSD leads to difficulties in personal and family relationships (8). Exposure to combat, overseas deployment, experiencing or participating in violence, and a service member's injuries or disabilities all have profound impacts on the functioning of the service member's family. Spouses of veterans with post-traumatic stress disorder report relationship and psychological distress in their families (9). Numerous studies have demonstrated that spouses of veterans with PTSD are at increased risk for experiencing psychological and marital distress (10). Marital satisfaction, quality of life, and mental health of people are dependent on their coping styles when exposed to traumatic events. Changes in coping styles and living conditions can lead to new challenges for the etiology of mental disorders (11). The maladaptive methods of coping with stress are increasingly widespread in people with mental disorders, and they may threaten the patient's mental health (12). Coping techniques help patients overcome personal conflicts, psychological and physical problems, and social difficulties (13). Consequently, recent efforts to determine the needs of spouses of veterans with PTSD should be evaluated and expanded. The families of veterans should plan for non-predictable life events and learn to cope with their traumas (9). Although many studies have shown that links exist between PTSD symptoms and marital dissatisfaction (14), some aspects of this problem remain unclear, and they can lead to dysfunctions in the family. Furthermore, it is unknown whether the treatments are effective in increasing marital satisfaction or quality of life, and few studies have examined the relationship between family therapy and couple therapy in increasing marital satisfaction, quality of life, and coping strategies (8). Thus, exploring and investigating methods to address this issue seem to be necessary $(15,16)$. The overall objective of our study was to conduct an experimental study to assess the effectiveness of coping-style-based training by cognitive behavior therapy techniques for the wives of patients to assess its impact on their marital satisfaction. The secondary aim of the study was the development of a training program of Cognitive Behavior Therapy (CBT) techniques.

\section{Material and Methods \\ 2.1. Sampling method}

In this study, the participants were selected from the spouses of veterans (Iraq-Iran war veterans) with PTSD. These veterans had psychiatric diagnosis of post-traumatic stress disorder according to DSM-IV-TR. The veterans whose spouses agreed to participate in this study were selected from The Veterans Foundation of Northern Khorasan, Iran, in 2015 . We choose 60 subjects to participate in this study by using the accessible sampling method if a subject had been determined to be eligible for the study at the baseline assessment. They were assigned randomly to either the study of the control group, so there were 30 subjects in each group.

\subsection{Inclusion criteria for veterans}

The inclusion criteria for this study were 1) lack of physical defects due to war injury, 2) lack of psychiatric disorders, such as psychosis or bipolar disorder, 3) positive screening of the veterans for PTSD by DSM-IV, and 4) the subject and his wife were living together in one home, i.e., the subjects did not live in another city or in a separate house from their wives, and they were not divorced or separated.

\subsection{Inclusion criteria for spouses of veterans}

The inclusion criteria for the wives of the veterans were ) being at least 18 years old, 2) lack of major psychiatric disorders, such as psychosis or bipolar disorder, 3) accepting the terms and conditions of the cognitive behavioral therapy, and 4) stability of medical and legal situations for the participants to fully participate in the study.

\subsection{Exclusion criteria}

The exclusion criteria were 1) being absent from more than three sessions in the CBT program and 2) partial completion of the questionnaires in the post-test.

\subsection{Research instrument and study variables}

In this study, we used the Enrich questionnaire, Enrich marital satisfaction questionnaire (short form), to determine marital satisfaction in spouses of veterans with PTSD. Olson (1989) developed this questionnaire, which is comprised of 47 questions for the evaluation of marital satisfaction (17). The questionnaire was translated into Persian by Mirkheshti (1996). In the Persian version of this questionnaire, Cronbach's alpha for women was calculated as 0.82 , and it was 0.92 for men, which showed the internal consistency of the questionnaire. The correlation coefficient between the scores of the participants on two occasions with an interval of three weeks was 0.88 for all subjects (18). 


\subsection{Experiment}

In the first stage, we asked the subjects to complete the Enrich questionnaire. The cognitive behavioral group therapy (CBT) was the chosen treatment program for spouses of veterans with PTSD, and it was administered effectively in the experimental groups. The treatment program consisted of three major modules, i.e., identifying negative thoughts, tackling negative thoughts, and undertaking behavioral activation (19). Following the protocol specified in the manual, the cognitive behavioral therapy was administered in 90-minute sessions over a 12-week period. CBT was a treatment consisting of several overlapping phases. In the current study, we used the training package entitled "Practical guide for Stress Management," which is based on the cognitive behavioral approach (20), to study the efficacy of the application of CBT in increasing marital satisfaction and decreasing stress. The short training sessions of coping with stress in cognitive behavioral therapy consisted of 10 sessions:

1) Session 1: an introduction to the training program and training of muscles. Progressive muscle relaxation is in 16 different muscle groups of the body and is a systematic technique for achieving a deep state of relaxation.

2) Session 2: identifying the effects of stress on five levels (cognitive, emotional, behavioral, physical, and social levels) and muscle relaxation training in eight different muscle groups of the body.

3) Session 3: understanding the relationship between thoughts and emotions along with muscle relaxation training in four different muscle groups of the body.

4) Session 4: identifying negative thoughts, breathing training, autogenes training, and training of passive muscle relaxation.

5) Session 5: replacing irrational thoughts with rational thoughts and relaxation training by the autogenes method.

6) Session 6: definition of coping skills and its variants along with auto genes training in order to control the heart rate, respiration, abdomen, and forehead.

7) Session 7: training coping skills and auto genes training with visualization and positive mood induction.

8) Session 8: defining anger, anger management, and meditation training.

9) Session 9: an introduction to strategies and styles of interpersonal conflict resolution accompanied by relaxation and meditation training by counting breaths.

10) Session 10: an explanation of the importance of social support and learning the techniques of stress management in order to maintain the social support.

Interventions were performed over a 12-week timeframe. After 3 months, all of the participants were re-assessed using the same Enrich questionnaire. The subjects completed the questionnaire, and the researchers investigated the changes in the marital satisfaction scores.

\subsection{Statistical analysis}

Descriptive analyses were conducted using the t-test for comparison of mean differences between two groups. Analysis of co-variance (ANCOVA) was used to determine the effect of CBT between the two groups. The data were analyzed using SPSS version 16 (SPSS, Inc. Chicago, Illinois, USA).

\subsection{Research ethics}

This study was conducted following the ethical standards of Iran's psychological associations. It was conducted with human subject protections and satisfying clinical practices and was approved by Bojnurd City College Committee. All participants provided informed written consent stating their willingness to participate in this study. In order to adhere to ethical standards, the control group was told that they would participate in cognitive behavioral therapy after three months.

\section{Results}

\subsection{Demographic characteristics}

According to the results of this study, in the study group, 6.6, 73.3, and $20.1 \%$ of the subjects were younger than 30 , between 30 and 45, and above 45, respectively. Also, in the control group 13.3\% of subjects were younger than 30, $73.3 \%$ were between 30 and 45, and $13.3 \%$ were above 45 . The mean and standard deviation of age were $36.8 \pm$ 4.33 years in the study group and $35.3 \pm 4.7$ years in the control group. Therefore, the t-test showed no significant difference between the mean ages of the two groups. The results of this study demonstrated that, in the study group, $6.6 \%$ of subjects had college degrees, $80 \%$ had a high school education or less, and 13.3\% were analphabetic. Also, in the control group, $6.6 \%$ had college degrees, $86.6 \%$ had a high school education or less, and $6.6 \%$ were analphabetic. The results of the financial status investigation indicated that none of participants had a high financial status. The results of this study showed that $60 \%$ of the veterans in the study group were employed and $40 \%$ were 
unemployed. In the control group, 53.4 and $46.6 \%$ of the veterans were employed and unemployed, respectively. All of the subjects were housekeepers, and none of them was employed.

\subsection{Examination of the efficacy of the treatment}

Treatment with cognitive behavioral group therapy showed evidence of clinical improvements in marital satisfaction. For the 25 subjects who completed the treatment, statistically-significant effects were observed in marital satisfaction. The distribution of mean and standard deviation of marital satisfaction in the control and study groups are shown in Table 1. We used the ANCOVA test to analyze the pre-test and post-test data. The results of these analyses are shown in Table 2. According to these analyses, the average pre-test that was adjusted by ANCOVA test was calculated as 122.67. Based on the results from Table 2, according to $F_{(1.28)}=20.383$ and $p<$ 0.005 , there was a significant effect on the women in the study group. As a result, the null hypothesis was rejected after adjusting the pre-test scores. In the current study, the results proved that there was a statistically-significant difference between the control and study groups in marital satisfaction $\left(\mathrm{F}_{(1.28)}=20.383\right)$. This means that CBT was effective in increasing marital satisfaction.

Table 1. Enrich marital satisfaction scores in control and study groups

\begin{tabular}{|l|l|l|l|}
\hline \multicolumn{2}{|l|}{ Groups } & Mean & Standard deviation \\
\hline Experimental & Pretest & 114.13 & 19.835 \\
\cline { 2 - 4 } & Posttest & 151.53 & 17.703 \\
\hline \multirow{2}{*}{ Control } & Pretest & 131.20 & 25.375 \\
\cline { 2 - 4 } & Posttest & 126.80 & 14.443 \\
\hline
\end{tabular}

Table 2. ANCOVA test of pre-test and post-test data

\begin{tabular}{|l|l|l|l|l|l|}
\hline Sources of variation & SS & MS & F & df & p \\
\hline Intercept & 12525.214 & 12525.214 & 49.891 & 1 & 0.0001 \\
\hline Group & 5108.528 & 5108.528 & 20.383 & 1 & 0.0001 \\
\hline Pretest & 529.708 & 529.708 & 2.110 & 1 & 0.158 \\
\hline Error & 6778.426 & 251.053 & & 27 & \\
\hline Total & 24941.876 & & & 30 & \\
\hline
\end{tabular}

\section{Discussion}

According to the basic premise of our study, post-traumatic stress disorder has negative effects on marriage and interpersonal communication. The quality of life and marital satisfaction of patients with advanced PTSD are much lower than they are for other people. The results of our study showed a low level of marital satisfaction in couples in which there was a veteran with PTSD. Consistent with our basic premise, Renshawa's study revealed that veterans with PTSD have more stress than other soldiers. According to the self-report questionnaires, they had lower levels of mental health (21). Also, the results of the study of Erbes et al. suggested a different pattern for the relationships between PTSD factors and the relationship adjustment among female soldiers (22). The results of Dekel and Solomon's study agreed with these findings (23). The results of our study demonstrated that methods of coping with stress according to CBT are effective in increasing the marital satisfaction of wives of veterans with PTSD. Consistent with our study, Davidson et al.'s study showed that methods of coping with stress, social-skill training, and interpersonal-relationship training are effective for the psychological well-being of children of veterans with PTSD (24). Creech et al. suggested that the strategies used to cope with combat stress may impact both PTSD and the functionality of the family. Moreover, it can highlight the potential utility of pre- and post-deployment coping skills training (25). Renshaw and Caska performed a study to investigate the role of partners' perceptions of posttraumatic stress symptom. The analyses of that study revealed that partners' perceptions of withdrawal/numbing symptoms were associated with greater distress, but perceptions of re-experiencing symptoms were associated significantly with lower levels of relationship distress (22). Iverson's study examined the impact of distinct PTSD symptom clusters, dissociation, and coping strategies on intimate partner violence (IPV) re-victimization among abused women. The findings suggested that coping strategies are important and can be potential predictors of physical IPV re-victimization (26). Consistent with our study, many studies have shown that coping styles for stress are effective in decreasing stress. Also, they lead to improved quality of life. The results of Mahmud et al. (27), Nikrahan et al. (28), Dekel et al. (29), and Sherman et al. (30) were consistent with our study. One study examined the effect of coping-style training on the mental health and stress reduction of Iranian staff. The results showed that coping style was effective in alleviating the depression of participants. Furthermore, other studies have explained how family coping has a direct relationship with stress level and decreasing life pressure of spouses of veterans with 
PTSD $(31,32)$. Therefore, as mentioned above, reduction of stress leads to increasing marital satisfaction. Coping strategies appear to be predictors of marital satisfaction. Indeed, coping strategies have a unique share in marital satisfaction. Recognizing and providing guidelines and techniques for lessening stress could be an important step toward enhancing family happiness, improving family interactions, and improving the quality of life. A causal pathway integrating these factors should be tested in future studies.

\section{Conclusions}

According to our paper, training of stress-coping strategies on marital satisfaction of spouses of veterans with posttraumatic stress disorder was significantly effective. Future research should focus on studies that can assist us in gaining a better understanding of the relationship between other mental disorders and family dysfunction. We can focus on family-centered interventions that can be effective in providing guidelines for increasing other factors of quality of life and mental health. Also future research should examine whether changes in types of coping strategies can be useful in the treatment of PTSD or other mental disorders.

\section{Acknowledgments:}

This manuscript was part of a research project conducted in the Addiction and Behavioral Sciences Research Center, North Khorasan University of Medical Sciences, Bojnurd, Iran (Ref. No.: 93/p/43448).

\section{Conflict of Interest:}

There is no conflict of interest to be declared.

Authors' contributions:

All authors contributed to this project and article equally. All authors read and approved the final manuscript.

\section{References:}

1) Zatzick DF, Marmar CR, Weiss DS, Browner WS, Metzler TJ, Golding JM, et al. Posttraumatic stress disorder and functioning and quality of life outcomes in a nationally representative sample of male Vietnam veterans. Am J Psychiatry. 1997; 154(12): 1690-5. PMID: 9396947.

2) Bowen A, Shelley M, Helmes E, Landman M. Disclosure of traumatic experiences, dissociation, and anxiety in group therapy for posttraumatic stress. Anxiety Stress Coping. 2010; 23(4): 449-61. doi: 10.1080/10615800903414315, PMID: 19916086.

3) Alonso J, Angermeyer M, Bernert S, Bruffaerts R, Brugha T, Bryson H, et al. Disability and quality of life impact of mental disorders in Europe: results from the European Study of the Epidemiology of Mental Disorders (ESEMeD) project. Acta Psychiatr Scand Suppl. 2004; 109(420): 38-46. PMID: 15128386.

4) Kyutoku Y, Tada R, Umeyama T, Harada K, Kikuchi S, Watanabe E, et al. Cognitive and psychological reactions of the general population three months after the 2011 Tohoku earthquake and tsunami. PloS one. 2012; 7(2): e31014. doi: 10.1371/journal.pone.0031014, PMID: 22347421, PMCID: PMC3275613.

5) Pence BW, Shirey K, Whetten K, Agala B, Itemba D, Adams J, et al. Prevalence of Psychological Trauma and Association with Current Health and Functioning in a Sample of HIV-infected and HIV-uninfected Tanzanian Adults. PloS one. 2012; 7(5): e36304. doi: 10.1371/journal.pone.0036304, PMID: 22606252, PMCID: PMC3351441.

6) Giacco D, Matanov A, Priebe S. Symptoms and subjective quality of life in post-traumatic stress disorder: a longitudinal study. 2013.

7) Richardson JD, Long ME, Pedlar D, Elhai JD. Posttraumatic stress disorder and health-related quality of life among a sample of treatment-and pension-seeking deployed Canadian Forces peacekeeping veterans. Can J Psychiatry. 2008; 53(9): 594-600. PMID: 18801222.

8) Ray SL, Vanstone M. The impact of PTSD on veterans' family relationships: An interpretative phenomenological inquiry. Int J Nurs Stud. 2009; 46(6): 838-47. doi: 10.1016/j.ijnurstu.2009.01.002, PMID: 19201406.

9) Link PE, Palinkas LA. Long-term trajectories and service needs for military families. Clin Child Fam Psychol Rev. 2013; 16(4): 376-93. doi: 10.1007/s10567-013-0145-z, PMID: 23828635.

10) Renshaw KD, Rodrigues CS, Jones DH. Psychological symptoms and marital satisfaction in spouses of Operation Iraqi Freedom veterans: relationships with spouses' perceptions of veterans' experiences and symptoms. J Fam Psychol. 2008; 22(4): 586. doi: 10.1037/0893-3200.22.3.586, PMID: 18729672.

11) Eadie TL, Bowker BC. Coping and quality of life after total laryngectomy. Otolaryngol Head Neck Surg. 2012; 146(6): 959-65. doi: 10.1177/0194599812437315, PMID: 22307574, PMCID: PMC3360982. 
12) Sesar K, Šimić N, Barišić M. Multi-type childhood abuse, strategies of coping, and psychological adaptations in young adults. Croat Med J. 2010; 51(5): 406-16. doi: 10.3325/cmj.2010.51.406, PMID: 20960590, PMCID: PMC2969135.

13) DeLongis A, Holtzman S. Coping in context: The role of stress, social support, and personality in coping. J pers. 2005; 73(6): 1633-56. doi: 10.1111/j.1467-6494.2005.00361.x, PMID: 16274448.

14) Nachar N, Guay S, Beaulieu-Prévost D, Marchand A. Assessment of the psychosocial predictors of healthrelated quality of life in a PTSD clinical sample. Traumatology. 2013; 19(1): 20. doi: 10.1177/1534765612438944, PMID: 23766669, PMCID: PMC3679041.

15) Ebrahimzadeh MH, Shojaei BS, Golhasani-Keshtan F, Soltani-Moghaddas SH, Fattahi AS, Mazloumi SM. Quality of life and the related factors in spouses of veterans with chronic spinal cord injury. Health Qual Life Outcomes. 2013; 11(8): 48. doi: 10.1186/1477-7525-11-48, PMID: 23506336, PMCID: PMC360791.

16) Renshaw KD, Blais RK, Caska CM. Distress in spouses of combat veterans with PTSD: The importance of interpersonally based cognitions and behaviors. Risk and resilience in US military families. Springer; 2010. p. 69-84.

17) Fowers BJ, Olson DH. Enrich Marital Inventory: A discriminant validity and cross - validation assessment. J Marital Fam Ther. 1989; 15(1): 65-79. doi: 10.1111/j.1752-0606.1989.tb00777.x, PMID: 21118433.

18) Zarei $\mathrm{E}$, Ahmadisarkhooni $T$. Relationships between spiritual quotient and marital satisfaction level of men, women and couples referred to consultancy centers of Bandar Abbas. Iran J Psychiatry Behav Sci. 2013; 7(1): 45-51. PMID: 24644499, PMCID: PMC3939985.

19) Foa EB, Keane TM, Friedman MJ, Cohen JA. Effective treatments for PTSD: practice guidelines from the International Society for Traumatic Stress Studies: Guilford Press; 2008.

20) Barlow DH, Lehrer PM, Woolfolk RL, Sime WE. Principles and practice of stress management: Guilford Press; 2007.

21) Renshaw KD, Rodebaugh TL, Rodrigues CS. Psychological and marital distress in spouses of Vietnam veterans: Importance of spouses' perceptions. J anxiety disord. 2010; 24(7): 743-50. doi: 10.1016/j.janxdis.2010.05.007, PMID: 20541905.

22) Erbes CR, Meis LA, Polusny MA, Compton JS. Couple adjustment and posttraumatic stress disorder symptoms in National Guard veterans of the Iraq war. J Fam Psychol. 2011; 25(4): 479. doi: 10.1037/a0024007, PMID: 21639633.

23) Dekel R, Solomon Z. Secondary traumatization among wives of Israeli POWs: the role of POWs' distress. Soc Psychiatry Psychiatr Epidemiol. 2006; 41(1): 27-33. doi: 10.1007/s00127-005-0002-6, PMID: 16341620.

24) Davidson AC, Mellor DJ. The adjustment of children of Australian Vietnam veterans: is there evidence for the transgenerational transmission of the effects of war-related trauma? Aust N Z J Psychiatry. 2001; 35(3): 345-51. doi: 10.1046/j.1440-1614.2001.00897.x, PMID: 11437808.

25) Creech SK, Benzer JK, Liebsack BK, Proctor S, Taft CT. Impact of coping style and PTSD on family functioning after deployment in Operation Desert Shield/Storm returnees. J Trauma Stress. 2013; 26(4): 507-11. doi: 10.1002/jts.21823, PMID: 23893396.

26) Iverson KM, Litwack SD, Pineles SL, Suvak MK, Vaughn RA, Resick PA. Predictors of intimate partner violence revictimization: The relative impact of distinct PTSD symptoms, dissociation, and coping strategies. J Trauma Stress. 2013; 26(1): 102-10. doi: 10.1002/jts.21781, PMID: 23417878.

27) Mahmoud JSR, Staten RT, Hall LA, Lennie TA. The relationship among young adult college students' depression, anxiety, stress, demographics, life satisfaction, and coping styles. Issues Ment Health Nurs. 2012; 33(3): 149-56. doi: 10.3109/01612840.2011.632708, PMID: 22364426.

28) Nikrahan G, Ganjeh SJ, Zarean E, Naghshineh E. Examining the relationship between big five personality factors, coping styles and depression in pregnant women. Elixir Psychology. 2012; 42: 6457-62.

29) Dekel R, Goldblatt H, Keidar M, Solomon Z, Polliack M. Being a Wife of a Veteran with Posttraumatic Stress Disorder. Family Relations. 2005; 54(1): 24-36. doi: 10.1111/j.0197-6664.2005.00003.x.

30) Sherman MD, Sautter F, Jackson MH, Lyons JA, Han X. Domestic violence in veterans with posttraumatic stress disorder who seek couples therapy. J Marital Fam Ther. 2006; 32(4): 479. doi: 10.1111/j.17520606.2006.tb01622.x, PMID: 17120520.

31) Jordan BK, Marmar CR, Fairbank JA, Schlenger WE, Kulka RA, Hough RL, et al. Problems in families of male Vietnam veterans with posttraumatic stress disorder. J Consult Clin Psychol. 1992; 60(6): 916-26. doi: 10.1037/0022-006X.60.6.916, PMID: 1460153.

32) Dekel R, Monson CM. Military-related post-traumatic stress disorder and family relations: Current knowledge and future directions. Aggress Violent Behav. 2010; 15(4): 303-9. doi: 10.1016/j.avb.2010.03.001. 